\title{
Introduction to Radar Scattering Application in Remote Sensing and Diagnostics: Review
}

\author{
Sidra Batool ${ }^{1, *} \mathbb{C}$, Fabrizio Frezza ${ }^{2}\left(\mathbb{D}\right.$, Fabio Mangini ${ }^{3}\left[{ }^{-}\right.$and Patrizio Simeoni ${ }^{4}$ \\ 1 Mathematical Models for Engineering, Electromagnetics and Nanosciences, "La Sapienza", \\ University of Rome, c/o DIET, Via Eudossiana 18, 00184 Rome, Italy \\ 2 Department of Information Engineering, Electronics, and Telecommunications, "La Sapienza", \\ University of Rome, Via Eudossiana 18, 00184 Rome, Italy; fabrizio.frezza@uniroma1.it \\ 3 Department of Information Engineering, University of Brescia, Via Branze 59, 25123 Brescia, Italy; \\ FABIO.MANGINI@unibs.it \\ 4 National Transport Authority (NTA), Harcourt Lane, D02WT20 Dublin, Ireland; xdebianx@gmail.com \\ * Correspondence: sidra.batool@uniroma1.it
}

Received: 30 March 2020; Accepted: 10 May 2020; Published: 18 May 2020

\begin{abstract}
The manuscript reviews the current literature on scattering applications of RADAR (Radio Detecting And Ranging) in remote sensing and diagnostics. This paper gives prime features for a variety of RADAR applications ranging from forest and climate monitoring to weather forecast, sea status, planetary information, and mapping of natural disasters such as the ones caused by earthquakes. Both the fundamental parameters involved in scattering mechanisms of RADAR applications and the factors affecting RADAR performances are also discussed.
\end{abstract}

Keywords: radar applications; scattering mechanisms; climate monitoring; sea status; natural disasters

\section{Introduction}

RADAR (or, simply radar) is a device able to measure angles, range, and velocity, of target objects. Radar, initially developed during World War II, following the Daventry experiment of 1935, evolved over the years [1] to cover many and complex applications: when approaching the radar topic, one is nowadays surrounded by a massive volume of documentation, and it may be difficult to grasp the radar technology, the challenges, and the possible applications, all at the same time. This paper aims to be a primer to radar scattering applications which allows a complete overview of the radar presenting the fundamental aspects of both technology and applications. The paper is divided into four main sections: the first section introduces the radar systems, the second section presents an overview of the common parameters and fundamental radar equations, the third section provides an overview of current radar remote-sensing applications, and the final section provides conclusions and gives the reader some insights into the future evolution of the radar technology.

\section{Introduction: The Radar System}

Radar can be equipped either with an active sensor which illuminates the objects, and in this case, it is defined as active, or with a passive sensor, which relies on external sources (e.g., natural fonts of energy such as Sun and stars), and in this case, the radar system is defined as passive. In the literature, active radars are usually addressed simply with the term radar. Active radar is known as bistatic if the receiving antenna differs from the transmitting one; otherwise, it is defined as monostatic. In this paper, we present applications of both active and passive radar systems. The (active) radar operates either by transmitting a continuous wave or trains of electromagnetic energy pulses: in the first case, we have the so-called Continuous Wave $(\mathrm{CW})$ radars, for instance, Stepped Frequency Continuous Wave 
(SFCW) radar, while in the second case radars are defined pulse radars. An alternative form of radar is represented by pulse-Doppler radar, which combines the features of the two radar systems previously mentioned. Independently of the particular waveform employed, the radar application can be briefly described as follows: the radar system transmits electromagnetic energy through the transmitting antenna, either in a preferred direction or in any direction. These radiated waves are reflected back, typically in all directions. A certain portion of the reflected radiated signal is received through the radar receiving antenna and processed through digital signal processing tools, which constitute the so-called reception chain: in Figure 1, a block diagram illustrating the basic working principle of a monostatic pulse radar is shown [2]. The transmitting chain is constituted by a pulse modulator and a power amplifier; those generate a signal that is transmitted by an antenna having the appropriate radiation pattern. The duplexer allows a single antenna to be used for both the signal transmission and reception; this element is therefore absent in bistatic radars. The first block in the receiving chain, following the receiving antenna (and eventually the duplexer), is represented either by a low-noise amplifier or by a mixer. The local oscillator and mixer convert the received Radio Frequency (RF) signals into Intermediate Frequency (IF) signals: in typical radar applications, such as air-surveillance, the IF amplifier has a center frequency of 30 or $60 \mathrm{MHz}$ with $1 \mathrm{MHz}$ bandwidth. The IF amplifier is designed as a matched filter (i.e., the Signal-to-Noise Ratio (SNR) at the output is maximized) for signal processing. Its objective is to separate the information (wanted signal) from noise (unwanted signal). Then, the radiated pulse modulated signal is captured by a second detector and amplified by a video amplifier, so that the signal can be eventually displayed on a screen [3]. The monostatic pulse radar uses the same antenna for both transmission and reception of signals. Radar that operates with pulse signal for detecting stationary targets is called pulse radar. Radar that operates with CW signal for detecting non-stationary targets is called CW radar (see Figure 2). It has two antennas: one antenna is used for transmitting the signal and the other antenna is used for receiving the signal. It produces an analog signal having a frequency of $f_{0}$. Local oscillator produces a signal having a frequency of $f_{l}$. The output of local oscillator is connected to the mixer. The output of CW transmitter is connected to both transmitting antenna and mixer. Mixer can produce both sum and difference of the frequencies that are applied to it. The signals having frequencies of $f_{0}$ and $f_{l}$ are applied to mixer. Thus, the mixer will produce the output having frequencies $f_{o}+f_{l}$ or $f_{o}-f_{l}$. As the name suggests, sideband filter allows a particular sideband frequencies either upper sideband frequencies or lower sideband frequencies. The IF amplifier detects the signal, which has Doppler frequency $f_{d}$. The doppler amplifier amplifies the signal, which is having Doppler frequency $f_{d}$. Indicator specifies the information related to relative velocity and whether the target is inbound or outbound, as shown in Figure 2. CW Doppler radars give an accurate measurement of relative velocities. We compare here pulse and CW radar. In the pulse radar system, a modulated pulse signal is used for transmission. Its performance is sometimes affected by the stationary targets. It cannot operate down to zero range. It requires comparatively higher transmitting power. CW radar system uses both modulated and unmodulated CW signals for transmission. Two separate antennas are used for transmission and reception. Unmodulated CW radar measures only the speed of the target but not the distance of the target from the radar. Its performance is unaffected by stationary targets. Because the receiver is $\mathrm{ON}$ all times, it can operate down to zero range [4].

Antennas are radiating components, transducers, that turn wave propagation into electrical signals (receiving antenna) and vice versa (transmitting antenna). Antennas in general, and radar antennas, in particular, can be defined by a well-known set of parameters such as effective aperture, directive antenna gain, and power gain $[5,6]$. Radars employ a variety of antenna designs, such as dipole, leaky-wave, horn, and patch, often configured to obtain specific patterns and achieve a certain mechanical design [7]. Mostly directive antennas tend to be used to detect weak signals. First, we introduce antennas radiation properties, and from which other antenna parameters are derived in Tables 1 and 2. 


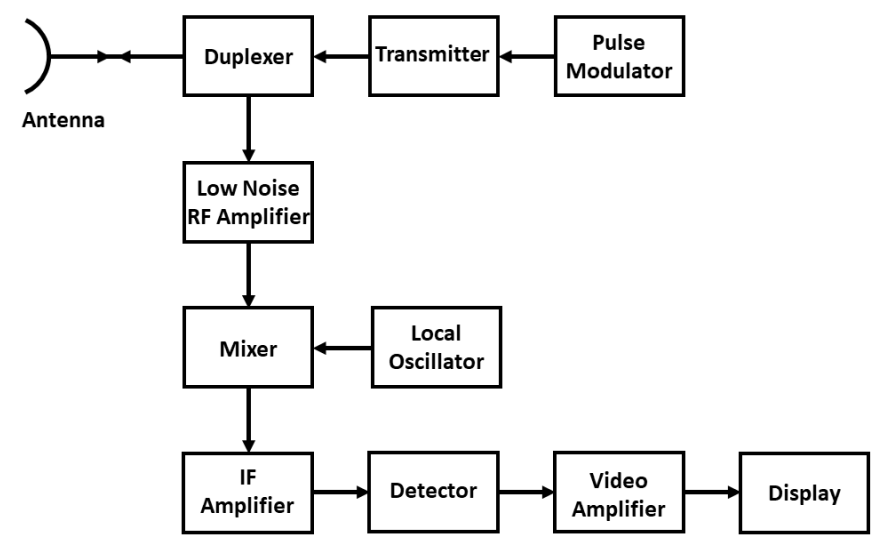

Figure 1. Block diagram of Pulse radar [4].

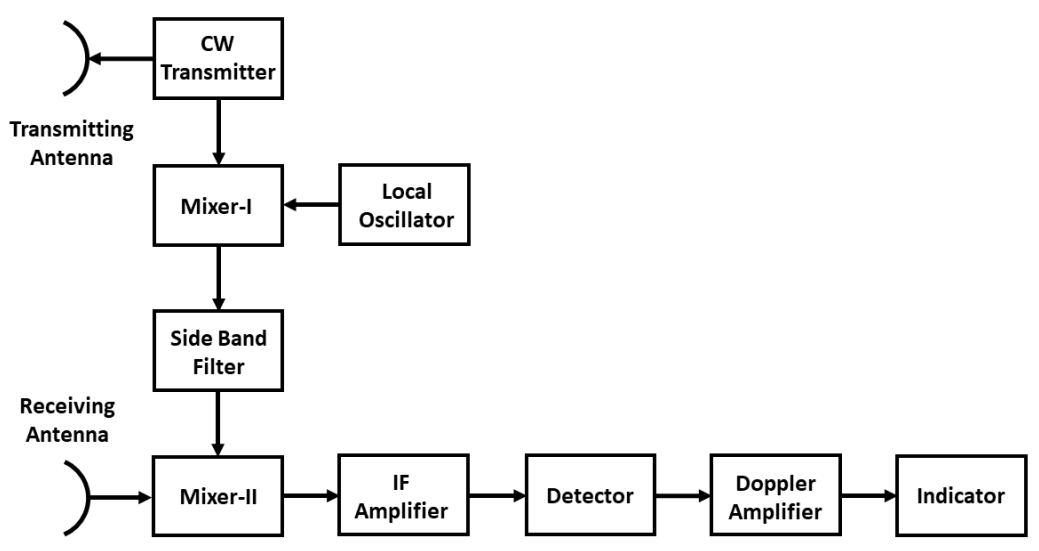

Figure 2. Block diagram of CW Doppler radar [4].

The electromagnetic wave radiated by the antenna carries electromagnetic power. The radiated power varies in magnitude, depending on both the direction of observation and the distance from the antenna. The electromagnetic power's general pattern is maintained in the far-field, regardless of the distance from the antenna. Therefore, we may introduce a normalized electromagnetic power density that will be independent of the distance from the antenna in the far-field. This is known as the radiation intensity. The radiation intensity is a mathematical description of the angular radiated power distribution in the far field (for a given polarization). In simpler terms, it is how much power is radiated by the antenna in a certain direction in the far field (using proper normalization with respect to the distance from the antenna). To describe mathematically, the radiation intensity, we have to define a way for representing directions. We associate steering angle with all directions. In our manuscript, we investigate the normalized intensity pattern of radar antennas. For this purpose, we take the mathematical formulations and arbitrary parametric values given in Tables 1 and 2. During our numerical test, we investigate the radiation pattern, which is comprised of lobes. These lobes are classified as follows: The lobe containing the direction of maximum radiation is referred to as the major lobe or the main beam. All other lobes are referred to as minor lobes. The main beam often represents the angular sector wherein the majority of the radiated power is intended to lay. The minor lobes, therefore, represent radiation in undesired directions and should be kept as low as possible, as shown in Figures 3 and 4. The simple design and fabrication of the circular dish reflectors allow those antennas to be widely used in microwave applications, and in particular in radar systems $[8,9]$. 
Table 1. Circular dish antenna [5].

\begin{tabular}{ccccc}
\hline \multicolumn{5}{c}{ Normalized Intensity Pattern Expression: $|E(\beta)|=\left|\frac{2 \pi r^{2} J(k r \sin \beta)}{k r \sin \beta}\right|$} \\
\hline$\#$ & Symbol & Description & Numerical Values for Input & Unit \\
\hline 1 & $\lambda$ & Wavelength & 0.1 & $m$ \\
2 & $d$ & Aperture diameter & 0.7 & $m$ \\
3 & $r$ & radius $=\frac{d}{2}$ & 0.35 & $m$ \\
4 & $k$ & Propagation constant $k=\frac{2 \pi}{\lambda}$ & 62.8320 & $m^{-1}$ \\
5 & $\beta$ & steering angle & $-\pi: \frac{\pi}{200}: \pi$ & $\mathrm{rad}$ \\
\hline
\end{tabular}

Table 2. Linear array antenna [5].

\begin{tabular}{ccccc}
\hline \multicolumn{7}{c}{ Normalized Intensity Pattern Expression: $|E(\sin \beta)|=\frac{1}{N}\left|\frac{\sin \left(N k d \sin \frac{\beta}{2}\right)}{k d \sin \frac{\beta}{2}}\right|$} & \\
\hline$\#$ & Symbol & Description & Numerical Values for Input & Unit \\
\hline 1 & $N$ & Number of elements in array & 8 & none \\
2 & $d$ & element spacing (e.g., $\left.d=\lambda, d=\frac{\lambda}{2}\right)$ & 5 & $m$ \\
3 & $\beta$ & steering angle & $\beta=10 \times \frac{\pi}{180}$ & degree \\
\hline
\end{tabular}

The far-field radiation pattern for the circular dish antenna of Table 1, computed as the modulus of the aperture factor, is displayed in Figure 3.

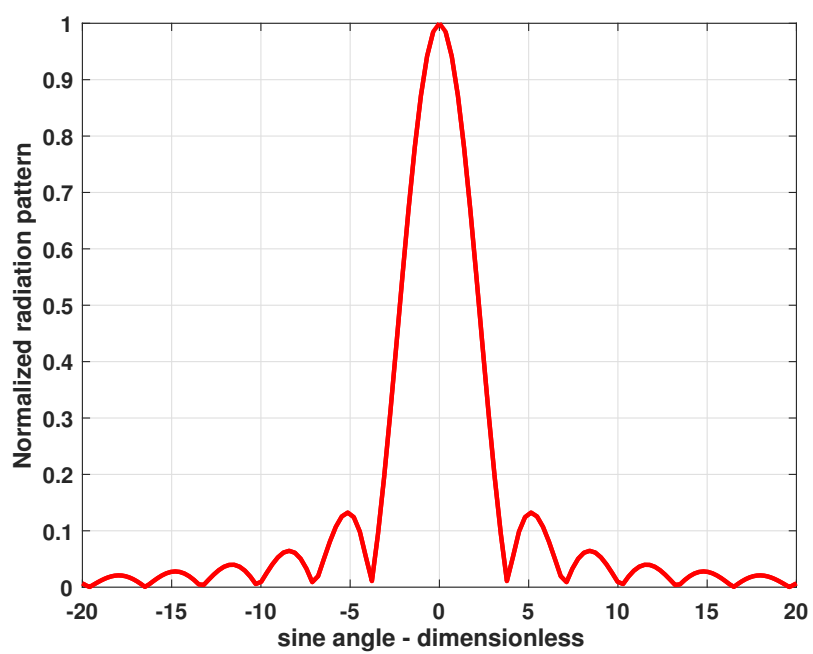

Figure 3. Radiation pattern for the circular aperture antenna of Table 1 computed using Matlab code.

Linear array antennas, such as the one described in Table 2, synthesize narrow directive beams that may be steered, either mechanically or electronically, in many different directions. In particular, electronic steering is achieved by controlling the phase of the array elements. Arrays with electronic beam steering capability are called phased-arrays antennas. A linear array is costly and complicated to design if compared to a circular dish antenna. However, the inherent flexibility of phased-array antennas to steer and control the beam shape represents an attractive feature for multi-function radar system manufacturing [10-14].

In Figure 4, the radiation pattern for the linear array is illustrated. The grating lobes, evident in the plot of Figure 4, get closer to the main beam when the distance $d$ between the elements increases. 


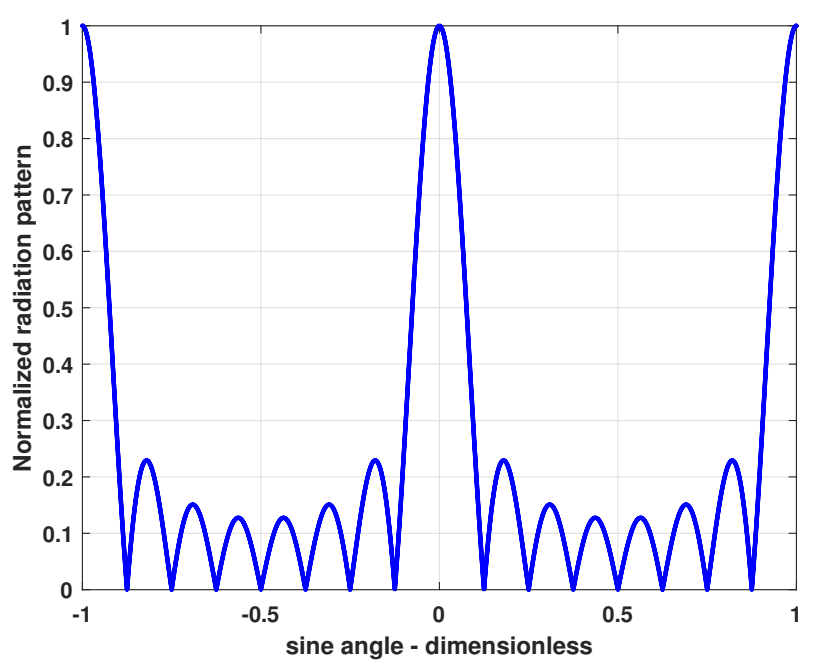

Figure 4. Radiation pattern for the linear array in Table 2.

The electromagnetic wave radiated by the antenna is a mixture of electric and magnetic fields. Polarization may be classified as linear, circular, or elliptical. Radar antennas are designed to transmit and receive signals at specific polarizations. The two most common forms of polarization employed in radar technology are horizontal linear polarization (or $\mathrm{H}$ ), and vertical linear polarization (or V) [15]; by convention, the "polarization" of electromagnetic waves refers to the direction of the electric field. Circular polarization is also used in some important radar applications, such as in weather radar applications $[16,17]$. Some antennas for radar systems are designed to receive and transmit signal on the same polarization (e.g., $\mathrm{HH}$ for horizontal receive and horizontal transmit and VV for vertical receive and vertical transmit), while some complex radar system antennas may be designed transmitting and receiving components working on different polarizations (e.g., HV for horizontal transmit and vertical receive and $\mathrm{VH}$ for vertical transmit and horizontal receive). Antennas for radar systems can present various levels of polarization combination, e.g., single-level polarization $(\mathrm{HH}, \mathrm{VV}, \mathrm{VH}$, or $\mathrm{HV})$, double-level polarization $(\mathrm{HH}, \mathrm{VV}$; $\mathrm{HH}, \mathrm{HV}$; or $\mathrm{VV}, \mathrm{VH})$, triple-level polarization $(\mathrm{HH}, \mathrm{VV}, \mathrm{HV}$ or $\mathrm{HH}$, $\mathrm{VV}, \mathrm{VH})$, and fourfold-level polarization ( $\mathrm{HH}, \mathrm{VV}, \mathrm{VH}, \mathrm{HV})$ [18-27].

\section{Radar Fundamental Equations and Parameters}

Radar range equation is helpful to investigate the radar characteristics and to determine the range resolution. It is also useful for designing and manufacturing of radar systems; the radar-range equation may be expressed as signal-to-noise ratio (SNR), and defined as follows [28]:

$$
S N R=\frac{P_{t} G^{2} \lambda^{2} \sigma}{(4 \pi)^{3} k T_{0} B F L R^{4}}
$$

The parameters introduced in the equation above are described in Table 3.

In Figure 5, some Matlab simulations are shown where symbols in Table 3 (e.g., frequency, peak power, bandwidth, and target cross section) are modified to provide the reader with an intuition on the effects of the different parameters on the radar range equation, here expressed in terms of SNR.

The range resolution, mentioned above in this paragraph, is the radar system ability to differentiate between two or more targets on the same bearer but at different ranges. The range resolution depends on the width of the transmitted signal, the target types and sizes, and the efficiency of the receiver and indicator elements. Pulse width is the primary resolution factor of a pulse radar. A well-designed radar 
system should be able to distinguish targets separated by half the pulse width-time $\tau$, when all other factors are at their maximum efficiency. The range $(R)$ equation for a pulse radar may be written as:

$$
R=\frac{c_{0} \tau}{2},
$$

where $c_{0}$ is the speed of light in a vacuum [29-31].
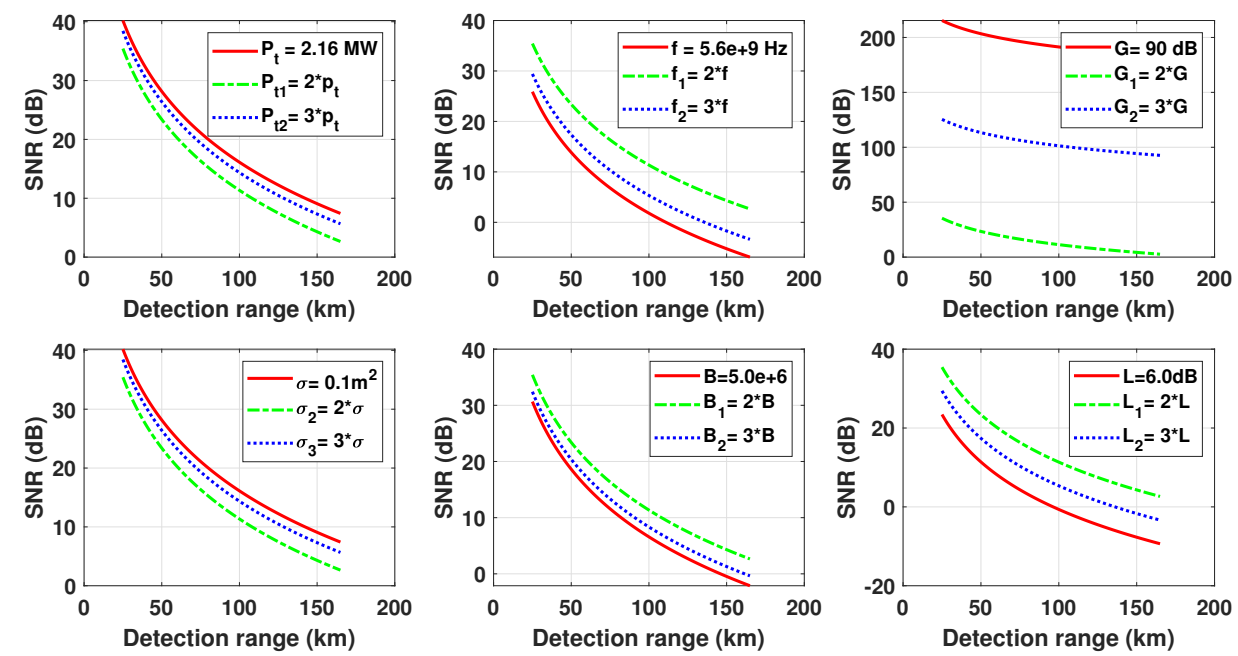

Figure 5. Matlab numerical simulation of the radar equation for different parametric values in Table 3.

Table 3. Parameters of the radar equation.

\begin{tabular}{ccccc}
\hline \multicolumn{5}{c}{ Parametric Values of the Radar Equation } \\
\hline$\#$ & Symbol & Description & Numerical Values for Input & Unit \\
\hline 1 & $P_{t}$ & Peak power & $2.16 \times 10^{6}$ & $\mathrm{~W}$ \\
2 & $f$ & radar center frequency & $5.6 \times 10^{9}$ & $\mathrm{~Hz}$ \\
3 & $c$ & Speed of light & $3.0 \times 10^{8}$ & $\mathrm{~ms}^{-1}$ \\
4 & $\lambda$ & Wavelength $=\frac{c}{f}$ & 0.0600 & $\mathrm{~m}^{-1}$ \\
5 & $k$ & Boltzmann's constant & $1.38 \times 10^{-23}$ & $\mathrm{JK}^{-1}$ \\
6 & $G$ & Antenna gain & 90.0 & $\mathrm{~dB}$ \\
7 & $\sigma$ & Target cross section & 0.1 & $\mathrm{~m}^{2}$ \\
5 & $B$ & Bandwidth & $8.0 \times 10^{6}$ & $\mathrm{~Hz}$ \\
6 & $F$ & noise figure & 3.0 & $\mathrm{~dB}$ \\
9 & $L$ & radar losses & 6.0 & $\mathrm{~dB}$ \\
10 & $T_{0}$ & Antenna temperature & 290.0 & $\mathrm{~K}$ \\
11 & $R$ & Target range & $R_{\text {min }}=25.0 \times 10^{3}, R_{\text {max }}=165.0 \times 10^{3}$ & $\mathrm{~km}$ \\
\hline
\end{tabular}

Another fundamental parameter is the radar operating frequency: as seen, radars radiate electromagnetic energy which, when reflected, allows us to detect and locate targets. Radars operating at different wavelengths (or energy bands, see Table 4, where the association between frequency ranges and energy bands is reported [2]) have different purposes: for instance, a C-band radar can penetrate through clouds and dust particles on the surface of the Earth, while an L-band radar can measure the GPS and soil moisture. $\mathrm{X}$ and Ku bands are commonly used for satellite communications. For certain applications, multiple energy bands have been explored: Toan et al. analyzed radar backscatter intensity from forest and they found the greatest intensity at P-band; the intensity would then decrease with the increase of frequency [32]. Different tree elements (leaves, branches, stems, etc.) using different frequency bands were studied by Picard [33] (see Table 5). A plant crowded with a large number of leaves and twigs can be investigated with higher frequency than what can happen for wilted plants. 
Radar incident angle is also a parameter which affects remote-sensing applications: it is defined as the angle between the direction of the incident radiation and the perpendicular to the target surface. Attema et al. studied the back-scattering produced by different kinds of plants in case of both dry soil and moist content. In particular, they observed plants on soil with different moisture employing radar at $\mathrm{X}$ and $\mathrm{Ku}$ bands, and, more specifically, frequencies between 8 and $18 \mathrm{GHz}$. They concluded that, in the case of a smooth surface, the backscatter was very sensitive to a near nadir incident angle, while, in the case of rough surfaces, the backscatter was almost independent of the incident angle [34].

Table 4. Radar frequency bands according to IEEE standards.

\begin{tabular}{ccc}
\hline$\#$ & Band Designation & Frequency Range \\
\hline 1 & $\mathrm{HF}$ & $3-30 \mathrm{MHz}$ \\
1 & $\mathrm{VHF}$ & $30-300 \mathrm{MHz}$ \\
2 & $\mathrm{UHF}$ & $300-3000 \mathrm{MHz}$ \\
3 & $\mathrm{~L}$ & $1-2 \mathrm{GHz}$ \\
4 & $\mathrm{~S}$ & $2-4 \mathrm{GHz}$ \\
5 & $\mathrm{C}$ & $4-8 \mathrm{GHz}$ \\
6 & $\mathrm{X}$ & $8-12 \mathrm{GHz}$ \\
7 & $\mathrm{Ku}$ & $12-18 \mathrm{GHz}$ \\
8 & $\mathrm{~K}$ & $18-27 \mathrm{GHz}$ \\
9 & $\mathrm{Ka}$ & $27-40 \mathrm{GHz}$ \\
10 & $\mathrm{~V}$ & $40-75 \mathrm{GHz}$ \\
11 & $\mathrm{~W}$ & $75-110 \mathrm{GHz}$ \\
12 & $\mathrm{~mm}$ & $110-300 \mathrm{GHz}$ \\
\hline
\end{tabular}

Table 5. Tree elements correspondence to the frequency of different radar bands.

\begin{tabular}{cccc}
\hline$\#$ & Main Scattering Area & Frequency Band & Frequency \\
\hline 1 & Leave Twigs & $X-B a n d$ & $8-12 \mathrm{GHz}$ \\
2 & Leaves and small branches & $C-B$ and & $4-8 \mathrm{GHz}$ \\
3 & Branches & $L-B$ and & $1-2 \mathrm{GHz}$ \\
4 & Trunk & VHF & $30-300 \mathrm{MHz}$ \\
\hline
\end{tabular}

The quality of a radar can be assessed also by its ability to identify the difference between target location and size $[35,36]$. Since signals transmitted by radars and reflected by objects find it difficult to enter the radar receiver, targets may remain undetected, and produce therefore a false negative, or signal interference can produce a false positive, also called false response or false alarm. Well-trained radar operators are not usually tricked by signal interference. Interference cannot be easily fixed by an automatic system of detection and tracking; it is usually necessary to detect and remove interference pulses before entering the automatic radar detector and tracker. Gurgel et al. studied several radars control and signal processing steps to overcome the interference. They reported an effective procedure to reduce the impact of Radio Frequency Interference (RFI) on the oceanographic measurements [37]. Haimovich et al. described the eigenanalysis methods used to overcome the interference problem $[38,39]$. A further parameter that is worth mentioning in this context is the radar receiver's sensitivity, which can be defined by the unavoidable noise at its input. This parameter has a great impact on the radar performances, and radar engineers often use an amplifier as the first stage of the receiver to improve the desired pulses and reduce noise and other unwanted signals. In particular, a designer tries to exaggerate the detection of weak signals using a "matched filter", i.e., a filter that maximizes the signal-to-noise ratio at the output of the receiver. The matched filter has an explicit mathematical formulation which depends on the input signal shape and the recipient noise character [40-42].

Finally, it is worth mentioning how radar images are affected by a target surface texture: radar images are composed of pixels and each pixel represents the amount of backscattered wave received from the surface of a given object. A surface can, in general, appear to a radar either as smooth or 
as rough, depending on both the frequency employed and the incidence angle. A smooth surface tends to reflect the energy in a single direction and generally away from the radar. For this reason, smooth surfaces tend to appear very dark in radar images. A rough surface, instead, tends to scatter an incident field in every direction; thus, a bigger portion of the radiation is statistically sent back to the radar system, and the images appear lighter. Therefore, in radar imaging, calm body water usually appears as dark. On the contrary, forest canopies, mountains, and buildings are generally rough and therefore tend to produce brighter images [43-45].

\section{Radar and Remote Sensing Applications}

In this section, a review of radar and remote sensing applications is provided. Every subsection goes through a specific application field.

\subsection{Forests Mapping}

Forests play a vital role in providing natural resources: they absorb carbon dioxide from the atmosphere and release oxygen, they provide natural habitats and food to animals, and they provide wood to humans. To monitor forests, radar and remote sensing techniques are employed, which allows acquiring very valuable data such as forest areas of disturbance [46], reckoning of land surface and budding volume of trees [47], and the measurement of the standard canopy height in the forests [48].

\subsection{Land, Wetland, and High-Earth Regions Mapping}

The wetland is a core element in the economic resources management of the world. It performs many beneficial activities for the global ecosystem. It helps us to reduce natural hurricanes, floods, and storms. Typically, optical and thermal remote sensors are applied for the land observation and for the identification of the major disturbing events such as severe storms and fires [49]. Among those are Geo eye [50], Rapid eye, Quick birds [51], Worldview satellites [52], and airborne remote sensors. Radar backscatter allows us to assess the dielectric properties of soil (dielectric constant) and to infer the surface layout (smooth vs rough surface). The dielectric constant is, in general, a complex quantity that can be expressed as a combination of two real quantities, the real permittivity and the conductivity [53]. Both are highly dependent on the media and provide a measurement of the electrical properties of a specific medium. In dry conditions, most naturally occurring media have a relative permittivity which assumes values in the range between 3 and 8 [54]. When water is added to dry soil, its permittivity increases and, as a consequence, the radar reflectivity also increases [55-59]. Radar Imaging can also be used to provide optical data of both wetland and upper region of the Earth [60]. Synthetic Aperture Radar (SAR) with its significant ability to penetrate the clouds is also used for day-night monitoring and measurement of wetland [61]. Ground-Penetrating Radar (GPR) is a particular radar technology used to investigate the "underground world". Depending on the application, the radar can use either air-coupling or ground-coupling antennas. GPR is employed in a variety of fields ranging from geophysical to civil engineering applications: for instance, it may be used for the analysis of wetland, rocks, pavements and structures analysis [62-64], underground water detection [65], or the study of ice sheets and the thickness of glaciers [66].

\subsection{Monitoring Photosynthetic Process for Plant Growth}

Satellite radar remote sensing can provide effective measurements associated closely with ecosystem process modeling [67], such as the initial growth of plants or the timing of seasonal snow-melt. A remote sensor is used to produce an annual estimation of natural processes such as photosynthesis and autotrophic respiration rates of evergreen forests [68]. Many modern applications benefit from using satellite microwave remote sensing, e.g., to record the timing and bad weather effect on Primary Net Production (PNP), to perform seasonal measurements of maximum and minimum $\mathrm{CO}_{2}$ concentrations, and to observe global climate. This study is beneficial for the process of increasing vegetation greenery and yearly plant productivity [69-72]. 


\subsection{Monitoring Earthquake Damages}

Stramondo et al. described the main features of remote sensing and optical satellite techniques for damage detection in rural areas. Different methods have been used either for damage assessment classification or for Earth surface measurements [73]. Satellite remote sensing can provide information that can be used to create a systematic framework providing deep knowledge of the Earth's surface. The geospatial information produced is then used as an input for addressing decisions in relation to comprehensive management, risk, and disaster assessment [74]. SAR can record the backscattering coefficient and to measure the condition of the outer Earth's surface. SAR can also measure damaged areas in disasters caused by earthquakes, flood, and forest fires [75,76]. Fialko et al. used Interferometric Synthetic Aperture Radar (InSAR) to find clear maps of three-dimensional surface displacement fields during the $1999 \mathrm{Mw} 7.1$ hector mine earthquake in Southern California [77]. Radar imaging capability features usually represent a significant aid to the rescue teams in the localization of the survivors in an earthquake [78].

\subsection{Alternative Radar and Imaging Systems}

A passive radar is an inherently unique case of bistatic radar. It uses a non-cooperative source to illuminate the objects; the passive radar then detects targets through the reflection of the energy generated by such a source and caused by the targets themselves [79,80]. Passive radar has been extensively used to describe the observation of geophysical and aerospace targets. Those radars can use commercial broadcast communication systems, such as Radio FM, analog TV, Digital Television (DTV), and navigation systems (GPS) [81-86]. Lidar is the acronym for Light detection and ranging, and it constitutes an alternative to the active remote sensing technology [87]. Lidar technology can measure 3D images of forest canopies accompanied with detailed topographic maps and accurate assessment of vegetable crown. Lidar is also used to estimate accurately high-biomass ecosystems and to predict forest standard structures [88]. Jacobe et al. described the cloud decomposition obtained by using imaging radar polarimetry technique for interpretation of the scattering from vegetation [60]. The recent development of polarimetric radar imaging and remote sensing can provide information regarding the Earth environment, damage assessment of the Earth, forest volume and height evaluation, glacier monitoring and mapping, and snowfall analysis [89]. Advanced polarimetric analysis techniques can also be used for speckle statistics, scattering polarization, and speckle filtering [90]. Synthetic-aperture radar (SAR) is an alternative and useful tool for processing coherent optical systems. This type of radar can provide finer-resolution images than conventional beam-scanning radars [91]. SAR is also considered an advanced tool to deal with the categorization of scattering from radar targets [92]. Wall imaging radar is an advanced Ultra Wideband (UW) communication tool that can be used to retrieve high-resolution images of detected objects, and it is based on short-pulse radar penetration through a wall surface [93].

\subsection{Monitoring Weather Forecast}

Combining radar and Global Positioning System (GPS) technologies, one can obtain useful information regarding atmospheric water vapor, operational weather forecasting, atmospheric storm systems, and global climate changes [61,94]. Aydin et al. reported a modern approach for the remote sensing of hail using an S-band dual linear polarization radar. The process employs a new hail signal HDR, which can be used for measurements of raindrop size distribution.

\subsection{Monitoring Terrestrial and Planetary Information}

A spaceborne radar can provide information about both terrestrial and planetary surfaces [95]. Radar astronomy allowed significantly improving our basic knowledge of planetary systems: for instance, a spacecraft radar system was applied in planetary missions to map the Venus surface (in a relatively low resolution) in the 1960s, and the unexpected 59.6-day rotation period of Mercury [96]. 
A major contribution to the investigation of the surface of Venus came from the upgrade of the Arecibo's radar system, which allowed analyzing the planet surface at a high resolution. In the literature, some recent astrometry-based activities are radial velocity measurement and the discovery of measuring the position of a solar system using image-based echo [97-100]. Saba et al. employed the Sardinian radio telescope as a radar for the study of near-Earth objects and Space Debris [101].

\subsection{Monitoring of the Sea Status}

Radar remote sensing techniques are being used in the measurement of the sea status. Radar satellite configurations employing ships, islands, and land-based stations are able to measure the ocean wave-height spectrum by employing a range of frequencies [102-107]. A promising and innovative approach was proposed by Zavorotny et al., who developed a theoretical model using the scattered Global Positioning System (GPS) signal as a function of geometrical and environmental parameters based on a bistatic radar equation. This study suggests that different time delays and different Doppler shifts of the scattered GPS signal may form small spatial cells relatively to the sea surface. This may allow an accurate evaluation of sea wind velocity [108], and, e.g., practical methods employing GPS followed [109].

\subsection{Monitoring of Human Body in Bio-Medical Applications}

Electromagnetic waves originated from UWB radars allow us to observe the intrinsic complex structure of the human body, and can, for instance, be employed to detect the movement of the heart wall [110]. The advanced technology of UWB radar systems allows today to monitor and assess many aspects of the human body: chest movements assessment, chest imaging, heart imaging, respiratory monitoring, non-invasive biomedical study of flexible tissues (e.g., brain), non-invasive study of metabolic processes, etc. [111].

The respiration rate of a healthy person is almost 12 breaths per minute [112]. Thus, the difference in breathing rate from maximum to minimum levels reveals the variation in human health condition and allows indicating whether a medical deliberation may be required, i.e., the evaluation of the respiration rate can help doctors in assessing the actual health condition. In addition, the normal heartbeat for a typical adult person lies between 60 and $100 \mathrm{bpm} \mathrm{[113].} \mathrm{If} \mathrm{the} \mathrm{heartbeat} \mathrm{rate} \mathrm{varies}$ from the typical limits, this may indicate the possible presence of diseases [114]. Thus, the assessment of the heartbeat rate can also help to visualize human health condition. Fadel et al. investigated both the human respiration and the heart rate, demonstrating that the radar can be used to measure even minor distances between the inhale and exhale processes of the human body during respiration [115].

\subsection{Scattering Mechanisms and Radar Observatory Techniques}

The polarimetric technique deals with the electromagnetic waves (polarization of the full-wave vector), throughout the frequency spectrum, by controlling the coherent polarization properties of the optical and radio waves: this allows detecting where there are either abrupt or gradual changes in the refraction index (or permittivity, magnetic permeability, and conductivity). When an electromagnetic wave passes from one medium to another, changing, therefore, refraction index, or when it strikes an object such as a radar target and it is reflected, it allows a polarization control to acquire knowledge of the characteristic information about the reflectivity, e.g., the orientation and shape of the reflecting object. In classical radars, i.e., amplitude-only radars, the information about a target is mainly obtained from the energy of the returned pulse; interferometric SAR exploits fully the phase and Doppler information, but not the polarization information of the electromagnetic vector wave-scatterer interrogation process [116-119].

A polarimetric, coherent electromagnetic scattering model has been developed for short-branch vegetation analysis. The polarimetric radar back-scatter analysis for soybean plants with truck-mounted scatterometer using L and C-band radar for different values of soil-humidity concentration was, in particular, performed by Yuzugullu et al. [120]. This model was used to investigate the soybean 
field's physical parameters, including soil moisture from a polarimetric set of AIRSAR images [121]. Using polarimetric SAR (PolSAR) data and electromagnetic scattering models depending on plant morphology, one can approximate the backscattering behavior of rice crops. The accuracy of such an approach has been tested in two different bands ( $X$ and $C$ ) with soil measured biophysical parameters in rice fields. Moreover, the proposed metamodel-based biophysical probabilistic parameter-retrieval algorithm has allowed rice crop height estimation using PolSAR data with both high accuracy and low computation cost [120]. Ferrazzoli et al. reported that the comparison between predicted performances of monostatic and bistatic radars in vegetation monitoring [122] shows the basic scattering mechanisms $[123,124]$. Robert et al. studied radar backscatter measurements of sea ice made in May 1977 with a surface-based FM-CW scatterometer from 1-2 to 8.5-17.5 GHz [125].

\section{Conclusions}

In this paper, a variety of radar and remote sensing applications are presented. Moreover, we illustrate some of the more crucial features of radar. Given the vast applications and the potential of this technology, both research and development of radar applications and techniques are constantly and steadily increasing. In the future, innovative radar system technologies will allow us to complete new features and applications, which can replace most of the existing ones in radar 2020 [126]. The future radar will be more informative, reliable, flexible, and less massive. The recent evolution in Artificial Intelligence, such as Deep Learning, promise to bring the radar imaging to new standards [127], improving detection and classification of targets (e.g., fall motion detection in-home monitoring [128], landmine detection [129], and ship discrimination [130]). Moreover, the advances in electronics may allow cost-effective radars (e.g., the GPR presented in [64]). In addition, the use of certain antenna technologies, mainly based on non-homogeneous waves, such as the so-called Leaky Wave Antennas [131], could lead to cheaper radars [132], and possibly also allow improving the radar penetration into lossy media $[133,134]$.

Author Contributions: S.B. conceived of the presented idea. S.B. developed the formulation or evolution of overarching research goals and aims. and performed the computations. F.F., F.M. and P.S. encouraged S.B. to investigate a specific aspect and supervised the findings of this work. All authors provided critical feedback and helped and equal contribution in the formation of the review article. All authors have read and agreed to the published version of the manuscript.

Funding: This research received no external funding.

Conflicts of Interest: All authors have no conflict of interest.

\section{References}

1. James, R.J. A history of radar. IEE Rev. 1989, 35, 343-349. [CrossRef]

2. Skolnik, F.; Merrill, I. Introduction to Radar: Radar Handbook; McGraw-Hill: New York, NY, USA, 1962.

3. Bhatta, N.P.; GeethaPriya, M. Radar and Its Applications; International Science Press: Cambridge, UK, 2017; Volume 10, pp. 1-9.

4. Devine, P. Radar Level Measurement: The Users Guide; Vega Controls: Burgess Hill, UK, 2000.

5. Josefsson, L.; Persson, P. Conformal Array Antenna Theory and Design; John Wiley and Sons: New York, NY, USA, 2006; Volume 10.

6. Balanis, C.A. Antenna Theory: Analysis and Design; John Wiley and Sons: New York, NY, USA, 2016.

7. Stutzman, W.L.; Thiele, G.A. Antenna Theory and Design; John Wiley and Sons: New York, NY, USA, 2012.

8. Li, Y.; Yang, L.; Gao, M.; Zhao, X.; Zhang, X. A study of a one-turn circular patch antenna array and the influence of the human body on the characteristics of the antenna. Ad Hoc Netw. 2020, 19, 102059. [CrossRef]

9. Dwivedi, R.P.; Khan, M.Z.; Kommuri, U.K. UWB circular cross slot AMC design for radiation improvement of UWB antenna. AEU-Int. J. Electron. Commun. 2020, 117, 153092. [CrossRef]

10. Wagh, K.; Shriramwar, S.S. Shriramwar, Performance enhancement of hexagonal-patch dual-band array antenna with omega-shaped DGS for dual Band radar Applications. Curr. Sci. 2020, 25, 249-254. 
11. Sultan, K.; Abdullah, H.; Abdallah, E.; Hennawy, E.L. MOM/GA-Based Virtual Array for radar Systems. Sensors 2020, 20, 713. [CrossRef]

12. Li, Y.; Wang, Z.; Pang, C.; Wang, X. A Low Cross-Polarization Configuration Method for Phased Array radar Antenna. Electronics 2020, 9, 396. [CrossRef]

13. Patwari, A.; Gudheti, R.R. Novel MRA-Based Sparse MIMO and SIMO Antenna Arrays for Automotive radar Applications. Prog. Electromagnet. Res. 2020, 86, 103-119. [CrossRef]

14. Baccarelli, P.; Burghignoli, P.; Frezza, F.; Galli, A.; Lampariello, P.; Lovat, G.; Paulotto, S. Effects of leaky-wave propagation in metamaterial grounded slabs excited by a dipole source. IEEE Trans. Microw. Theory Tech. 2005, 17, 32-44. [CrossRef]

15. Freeman, A.; Durden, S.L. A three-component scattering model for polarimetric SAR data. IEEE Trans. Geosci. Remote Sens. 1998, 36, 963-973. [CrossRef]

16. Antar, Y.M.M.; Hendry, A.; McCormick, G.C. Circular polarization for remote sensing of precipitation: Polarization diversity work at the National Research Council of Canada. IEEE Antennas Propag. Mag. 1992, 34, 7-16. [CrossRef]

17. Krehbiel, P.; Chen, T.; McCrary, S.; Rison, W.; Gray, G.; Brook, M. The use of dual channel circular-polarization radar observations for remotely sensing storm electrification. Meteorol. Atmos. Phys. 1996, 59, 65-82. [CrossRef]

18. Henry, J.B.; Chastanet, P.; Fellah, K.; Desnos, Y.L. Envisat multi-polarized ASAR data for flood mapping. Int. J. Remote Sens. 2006, 27, 1921-1929. [CrossRef]

19. Baghdadi, N.; Holah, N.; Zribi, M. Soil moisture estimation using multi-incidence and multi-polarization ASAR data. Int. J. Remote Sens. 2006, 27, 1907-1920. [CrossRef]

20. Inoue, Y.; Kurosu, T.; Maeno, H.; Uratsuka, S.; Kozu, T.; Dabrowska, K.; Qi, J. Season-long daily measurements of multifrequency $(\mathrm{Ka}, \mathrm{Ku}, \mathrm{X}, \mathrm{C}$, and $\mathrm{L})$ and full-polarization backscatter signatures over paddy rice field and their relationship with biological variables. Remote Sens. Environ. 2002, 81, 194-204. [CrossRef]

21. Haykin, S.; Krasnor, C.; Nohara, T.J.; Currie, B.W.; Hamburger, D.A. A coherent dual-polarized radar for studying the ocean environment. IEEE Trans. Geosci. Remote Sens. 1991, 29, 189-191. [CrossRef]

22. Chen, J.; Lin, H.; Pei, Z. Application of ENVISAT ASAR data in mapping rice crop growth in Southern China. IEEE Geosci. Remote Sens. Lett. 2007, 4, 431-435. [CrossRef]

23. Frezza, F.; Mangini, F. Electromagnetic scattering of an inhomogeneous elliptically polarized plane wave by a multilayered sphere. J. Electromagnet. Waves Appl. 2016, 30, 492-504. [CrossRef]

24. Frezza, F.; Mangini, F. Vectorial spherical-harmonics representation of an inhomogeneous elliptically polarized plane wave. JOSA A 2015, 32, 1379-1383. [CrossRef]

25. Frezza, F.; Mangini, F.; Muzi, M.; Stoja, E. In silico validation procedure for cell volume fraction estimation through dielectric spectroscopy. J. Biol. Phys. 2015, 41, 223-234. [CrossRef]

26. Batool, S.; Naqvi, Q.A.; Fiaz, M.A. Scattering from a cylindrical obstacle deeply buried beneath a planar non-integer dimensional dielectric slab using Kobayashi potential method. Optik-Int. J. Light Electron Opt. 2018, 1, 95-108. [CrossRef]

27. Batool, S.; Frezza, F.; Mangini, F.; Xu, Y.L. Scattering from multiple PEC sphere using Translation Addition Theorems for Spherical Vector Wave Function. J. Quant. Spectrosc. Radiat. Transf. 2020, 106905. [CrossRef]

28. Mahafza, R.; Bassem, R. Radar Systems Analysis and Design Using MATLAB, 2nd ed.; Chapman and Hall-CRC: Boca Rotan, FL, USA, 2005; Volume 10.

29. Scheer, J.; Holm, W.A. Principles of Modern Radar; Science and Technology Publishing: Shanghai, China, 2010; Volume 1.

30. Nezlin, D.V.; Kostylev, V.I.; Blyakhman, A.B.; Ryndyk, A.G.; Myakinkov, A.V. Bistatic Radar Principles and Practice; John Wiley and Sons: New York, NY, USA, 2007.

31. Alabaster, C. Pulse Doppler Radar; The Institution of Engineering and Technology: Stevenage, UK, 2012; Volume 2.

32. Le Toan, T.; Beaudoin, A.; Riom, J.; Guyon, D. Relating forest biomass to SAR data. IEEE Trans. Geosci. Remote Sens. 1992, 30, 403-411. [CrossRef]

33. Picard, G.; Martinez, J.M.; Melon, P.; Davidson, M. On the relationships between radar measurements and forest structure and biomass. Retr. Bio-Geo-Phys. Parameters SAR Data Land Appl. 2002, 475, 3-12.

34. Attema, E.P.; Ulaby, F.T. Vegetation modeled as a water cloud. Radio Sci. 1978, 13, 357-364. [CrossRef] 
35. Goodman, J.W. Some effects of target-induced scintillation on optical radar performance. Proc. IEEE 1965, 53, 1688-1700. [CrossRef]

36. Munshi, A.; Unnikrishnan, S. Performance Analysis of radar based on DS BPSK modulation technique. Int. J. Electron. Commun. Eng. Technol. (IJECET) 2013, 4, 137-143.

37. Gurgel, K.W.; Barbin, Y.; Schlick, T. Radio frequency interference suppression techniques in FMCW modulated HF radars. Oceans 2007, 7, 1-4.

38. Haimovich, A.M.; Bar Ness, Y. An eigenanalysis interference canceler. IEEE Trans. Signal Process. 1991, 39, 76-84. [CrossRef]

39. Vaghela, S.; Ravirajsinh, A.; Gonsai, A. Filter design for improvement of interference on adjacent frequency. Int. J. Electron. Commun. Eng. Technol. 2017, 8, 10-16.

40. Marcum, J. A statistical theory of target detection by pulsed radar. IRE Trans. Inf. Theory 1960, 6, 59-267. [CrossRef]

41. Robey, F.C.; Fuhrmann, D.R. A CFAR adaptive matched filter detector. IEEE Trans. Aerosp. Electron. Syst. 1992, 28, 208-216. [CrossRef]

42. Bevilacqua, A.; Niknejad, A.M. An ultrawideband CMOS low-noise amplifier for 3.1-10.6-GHz wireless receivers. IEEE J. Solid-State Circuits 2004, 39, 2259-2268. [CrossRef]

43. Apel, J.R. An improved model of the ocean surface wave vector spectrum and its effects on radar backscatter. J. Geophys. Res. Ocean. 1994, 99, 16269-16291. [CrossRef]

44. Davidson, M.W.; Toan, T.L.; Mattia, F.; Satalino, G.; Manninen, T.; Borgeaud, M. On the characterization of agricultural soil roughness for radar remote sensing studies. IEEE Trans. Geosci. Remote Sens. 2000, 38, 630-640. [CrossRef]

45. Long, M.W. Radar Reflectivity of Land And Sea; Artech House: Norwood, MA, USA, 1975; Volume 390, pp. 1-10.

46. Dubois, P.C.; Van Zyl, J.; Engman, T. Measuring soil moisture with imaging radars. IEEE Trans. Geosci. Remote Sens. 1995, 33, 915-926. [CrossRef]

47. Popescu, S.C. Estimating biomass of individual pine trees using airborne lidar. Biomass Bioenergy 2007, 31, 646-655. [CrossRef]

48. Lee, W.J.; Lee, C.W. Forest canopy height estimation using multiplatform remote sensing dataset. J. Sens. 2018, 10, 1-9. [CrossRef]

49. Klemas, V.V. The role of remote sensing in predicting and determining coastal storm impacts. J. Coast. Res. 2009, 9, 1264-1275. [CrossRef]

50. Aguilar, M.A.; del Mar, S.M.; Aguilar, F.J. Assessing geometric accuracy of the orthorectification process from GeoEye-1 and WorldView-2 panchromatic images. Int. J. Appl. Earth Obs. Geoinf. 2013, 21, 427-435. [CrossRef]

51. Tu, M.T.; Hsu, C.L. An adjustable pan-sharpening approach for IKONOS/QuickBird/GeoEye-1/WorldView-2 imagery. IEEE J. Sel. Top. Appl. Earth Obs. Remote Sens. 2012, 5, 125-134. [CrossRef]

52. Mutanga, O.; Adam, E. High density biomass estimation for wetland vegetation using WorldView-2 imagery and random forest regression algorithm. Int. J. Appl. Earth Obs. Geoinf. 2012, 18, 399-406. [CrossRef]

53. Mangini, F.; Dinia, L.; Frezza, F. Electromagnetic Scattering by a Cylinder in a Lossy Medium of an Inhomogeneous Elliptically Polarized Plane Wave. J. Telecommun. Inf. Technol. 2019, 4, 36-42. [CrossRef]

54. Martinez, A.; Brynes, A.P. Modeling Dielectric-Constant Values of Geologic Materials: An Aid to Ground-Penetrating Radar Data Collection and Interpretation; Kansas Geological Survey: Lawrence, KS, USA, 2001; p. 247.

55. Hasted, J.B. Aqueous Dielectrics; Chapman and Hall: London, UK, 1973.

56. Weir, W.B. Automatic measurement of complex dielectric constant and permeability at microwave frequencies. Proc. IEEE 1974, 62, 33-36. [CrossRef]

57. Kovacs, A.; Gow, A.J.; Morey, R.M. The in-situ dielectric constant of polar firn revisited. Cold Reg. Sci. Technol. 1995, 23, 245-256. [CrossRef]

58. Oh, Y.; Sarabandi, K.; Ulaby, F.T. An inversion algorithm for retrieving soil moisture and surface roughness from polarimetric radar observation. In Proceedings of the Geoscience and Remote Sensing Symposium (IGARSS'94), Pasadena, CA, USA, 8-12 August 1994; Volume 3, pp. 1582-1584.

59. Weiler, K.W. Comparison of ground penetrating radar and time-domain reflectometry as soil water sensors. Soil Sci. Soc. Am. J. 1998, 62, 1237-1239. [CrossRef] 
60. Van Zyl, J.J. Application of Cloude's target decomposition theorem to polarimetric imaging radar data and radar polarimetry. Int. Soc. Opt. Photonics 1993, 17, 184-192.

61. Massonnet, D.; Feigl, K.L. Radar interferometry and its application to changes in the Earth's surface. Rev. Geophys. 1998, 36, 441-500. [CrossRef]

62. Davis, J.L.; Annan, A.P. Ground-Pennetrating radar for high-resolution mapping of soil and rock stratigraphy. Geophys. Prospect. 1989, 37, 531-551. [CrossRef]

63. Mangini, F.; Di Gregorio, P.P.; Muzi, M.; Pajewski, L.; Frezza, F. Wire-Grid modeling of metallic targets for Ground Penetrating radar applications. In Proceedings of the IMEKO International Conference on Metrology for Archaeology and Cultural Heritage, Lecce, Italy, 23-25 October 2017; pp. 105-108.

64. Ferrara, V.; Troiani, F.; Frezza, F.; Mangini, F.; Pajewski, L.; Simeoni, P.; Tedeschi, N. Design and realization of a cheap Ground Penetrating radar prototype 2.45 GHz. In Proceedings of the 2016 10th European Conference on Antennas and Propagation (EuCAP), Davos, Switzerland, 10-15 April 2016; pp. 1-4. [CrossRef]

65. Afshar, A.; Abedi, M.; Norouzi, G.-H.; Riahi, M.A. Geophysical investigation of underground water content zones using electrical resistivity tomography and ground penetrating radar: A case study in Hesarak-Karaj. Iran. Eng. Geol. 2015, 196, 183-193. [CrossRef]

66. Kitov, A.D.; Ivanov, E.N.; Plyusnin, V.M.; Gladkov, A.S.; Lunina, O.V.; Serebryakov, E.V.; Afon'kin, A.M. Georadar Investigations of the Peretolchin Glacier (Southern Siberia). Geogr. Nat. Resour. 2018, 39, 55-62. [CrossRef]

67. Running, S.W.; Way, J.B.; Yang, Y.; Ali, E.E.; Badawi, A. Radar remote sensing proposed for monitoring freeze-thaw transitions in boreal regions. Trans. Am. Geophys. Union 1999, 80, 213-221. [CrossRef]

68. Kimball, J.S.; McDonald, K.C.; Running, S.W.; Frolking, S.E. Satellite radar remote sensing of seasonal growing seasons for boreal and subalpine evergreen forests. Remote Sens. Environ. 2004, 90, 243-258. [CrossRef]

69. McDonald, K.C.; Kimball, J.S.; Njoku, E.; Zimmermann, R.; Zhao, M. Variability in springtime thaw in the terrestrial high latitudes: Monitoring a major control on the biospheric assimilation of atmospheric $\mathrm{CO}_{2}$ with spaceborne microwave remote sensing. Earth Interact. 2004, 8, 1-23. [CrossRef]

70. Kasischke, E.S.; Melack, J.M. The use of imaging radars for ecological applications a review. Remote Sens. Environ. 1997, 59, 141-156. [CrossRef]

71. Way, J.; Zimmermann, R.; McDonald, K.; Oren, R. Winter and spring thaw as observed with imaging radar at BOREAS. J. Geophys. Res. Atmos. 1997, 102, 29673-29684. [CrossRef]

72. Karlsen, S.R.; Tolvanen, A.; Poikolainen, J.; HOgda, K.A.; Johansen, B.; Danks, F.S.; Aspholm, P.; Wielgolaski, F.E.; Makarova, O. MODIS-NDVI-based mapping of the length of the growing season in northern Fennoscandia. Int. J. Appl. Earth Obs. Geoinf. 2008, 10, 253-266. [CrossRef]

73. Stramondo, S.; Bignami, C.; Chini, M.; Pierdicca, N.; Tertulliani, A. Satellite radar and optical remote sensing for earthquake damage detection: Results from different case studies. Int. J. Remote Sens. 2006, 27, 4433-4447. [CrossRef]

74. Tralli, M.; David, R.G.; Blom, V.; Zlotnicki, A.; Donnellan, D.L.; Evans, D.L. Satellite remote sensing of earthquake, volcano, flood, landslide and coastal inundation hazards. ISPRS J. Photogramm. Remote Sens. 2005, 59, 185-198. [CrossRef]

75. Matsuoka, M.; Yamazaki, F. Use of satellite SAR intensity imagery for detecting building areas damaged due to earthquakes. Earthq. Spec. 2004, 20, 975-994. [CrossRef]

76. Michel, R.; Avouac, J.P. Measuring ground displacements from SAR amplitude images: Application to the Landers earthquake. Geophys. Res. Lett. 1999, 26, 875-878. [CrossRef]

77. Fialko, Y.; Simons, M. The complete (3-D) surface displacement field in the epicentral area of the 1999 Mw7.1 Hector Mine earthquake, California, from space geodetic observations. Geophys. Res. Lett. 2001, 28, 3063-3066.

78. Rathje, E.M.; Adams, B.J. The role of remote sensing in earthquake science and engineering opportunities and challenges. Earthq. Spec. 2008, 24, 471-492. [CrossRef]

79. Colone, F.; Hagan, D.W.O.; Lombardo, P.; Baker, C.J. A multistage processing algorithm for disturbance removal and target detection in passive bistatic radar. IEEE Trans. Aerosp. Electron. Syst. 2009, 45, 698-722. [CrossRef]

80. Colone, F.; Falcone, P.; Bongioanni, C.; Lombardo, P. WiFi-Based passive bistatic radar: Data processing schemes and experimental results. IEEE Trans. Aerosp. Electron. Syst. 2012, 48, 1061-1079. [CrossRef] 
81. Tan, D.K.P.; Sun, H.; Lu, Y.; Lesturgie, M.; Chan, H.L. Passive radar using global system for mobile communication signal: Theory, implementation and measurements. IEEE Proc.-Radar Sonar Navig. 2005, 3, 116-123. [CrossRef]

82. Griffiths, H.D.; Garnett, A.J.; Baker, C.J.; Keaveney, S. Bistatic radar using satellite-borne illuminators of opportunity. Int. Conf. Radar 1992, 92, 276-279.

83. Berger, C.R.; Demissie, B.; Heckenbach, J.; Willett, P.; Zhou, S. Signal processing for passive radar using OFDM waveforms. IEEE J. Sel. Top. Signal Process. 2010, 4, 226-238. [CrossRef]

84. Saini, R.; Cherniakov, M. DTV signal ambiguity function analysis for radar application. IEEE Proc.-Radar Sonar Navig. 2005, 152, 133-142. [CrossRef]

85. Sun, W.; Sahr, J.D.; Goodson, T. Digital demodulation of DTV signals for passive radar application. In Proceedings of the IEEE Radar Conference (RadarConf), Philadelphia, PA, USA, 2-6 May 2016; pp. 1-6.

86. Barott, W.C.; Engle, J. Single-antenna ATSC passive radar observations with remodulation and keystone formatting. In Proceedings of the IEEE Radar Conference, Cincinnati, OH, USA, 19-23 May 2014; pp. 159-163.

87. Fuling, B.; Guobin, Z.; Jun, L.; Xiaojun, T. Three dimensional data structure and data model. Geo-Spat. Inf. Sci. 2000, 1, 19-23. [CrossRef]

88. Lefsky, M.A.; Cohen, W.B. Lidar remote sensing for ecosystem studies, Lidar an emerging remote sensing technology that directly measures the three-dimensional distribution of plant canopies, can accurately estimate vegetation structural attributes and should be of particular interest to forest, landscape, and global ecologists. AIBS Bull. 2002, 52, 19-30.

89. Evans, D.L.; Farr, T.G.; Van Zyl, J.J.; Zebker, H.A. Radar polarimetry: Analysis tools and applications. IEEE Trans. Geosci. Remote Sens. 1988, 26, 774-789. [CrossRef]

90. Lee, J.S.; Pottier, E. Polarimetric Radar Imaging: From Basics to Applications; CRC Press: Boca Raton, FL, USA, 2009.

91. Cutrona, L.J.; Leith, E.N.; Porcello, L.J.; Vivian, W.E. On the application of coherent optical processing techniques to synthetic-aperture radar. Proc. IEEE 1966, 54, 1026-1032. [CrossRef]

92. Berizzi, F.; Corsini, G. Autofocusing of inverse synthetic aperture radar images using contrast optimization. IEEE Trans. Aerosp. Electron. Syst. 1996, 32, 1185-1191. [CrossRef]

93. Mahfouz, M.; Fathy, A. See-through-wall imaging using ultra wideband short-pulse radar system. Antennas Propag. Soc. Int. Symp. 2005, 3, 334-337.

94. Bevis, M.; Businger, S.; Herring, T.A.; Rocken, C.; Anthes, R.A.; Ware, R.H. GPS meteorology: Remote sensing of atmospheric water vapor using the Global Positioning System. J. Geophys. Res. Atmos. 1992, 97, 15787-15801. [CrossRef]

95. Elachi, C. Spaceborne Radar Remote Sensing: Applications and Techniques; IEEE Press: New York, NY, USA, 1988; p. 285.

96. Campbell, B.A. Radar Remote Sensing of Planetary Surfaces; Cambridge University Press: Cambridge, UK, 2002; p. 10.

97. Hagfors, T. Backscattering from an undulating surface with applications to radar returns from the Moon. J. Geophys. Res. 1964, 69, 3779-3784. [CrossRef]

98. Zebker, H.A.; Amelung, F.; Jonsson, S. Remote sensing of volcano surface and internal processes using radar interferometry. Remote Sens. Act. Volcan. 2000, 5, 179-205.

99. Lorell, J.; Born, G.H.; Christensen, E.J.; Esposito, P.B.; Jordan, J.F.; Laing, P.A.; Sjogren, W.L.; Wong, S.K.; Reasenberg, R.D.; Slater, G.L. Gravity field of Mars from Mariner 9 tracking data. Icarus 1973, 18, 304-316. [CrossRef]

100. Boerner, W.M.; Mott, H.; Luneburg, E. Polarimetry in remote sensing: Basic and applied concepts. In Proceedings of the IEEE International Geoscience Remote Sensing-A Scientific Vision for Sustainable Development, Singapore, 3-8 August 1997; Volume 3, pp. 1401-1403.

101. Saba, L.; Di Martino, M.; Delb, M.; Cellino, A.; Zappal, V.; Montebugnoli, S.; Righini, S.; Zoni, L.; Orosei, R.; Tosi, F.; et al. The Sardinian Radio Telescope as radar for the study of near-Earth Objects and Space Debris. Mem. Della Soc. Astron. Italiana Suppl. 2005, 6, 104-109.

102. Barrick, D. Remote sensing of sea state by radar: Engineering in the Ocean Environment. In Proceedings of the Ocean 72-IEEE International Conference on IEEE, Brighton, UK, 13-15 September 1972.

103. Srokosz, M.A. On the joint distribution of surface elevation and slopes for a nonlinear random sea with an application to radar altimetry. J. Geophys. Res. Ocean. 1986, 91, 995-1006. [CrossRef] 
104. Earl, G.; Ward, B. Frequency management support for remote sea-state sensing using the Jindalee skywave radar. IEEE J. Ocean. Eng. 1986, 11, 164-173. [CrossRef]

105. Komjathy, A.; Maslanik, J.; Zavorotny, V.U.; Axelrad, P.; Katzberg, S.J. Sea ice remote sensing using surface reflected GPS signals. In Proceedings of the IGARSS IEEE International Geoscience and Remote Sensing Symposium, Hampton, VA, USA, 24-28 July 2000; Volume 7, pp. 2855-2857.

106. Mullen, L.; Herczfeld, P.R. Application of radar technology to aerial LIDAR systems for enhancement of shallow underwater target detection. IEEE Trans. Microw. Theory Tech. 1995, 43, 2370-2377. [CrossRef]

107. Donelan, M.A.; Pierson, W.J. Radar scattering and equilibrium ranges in wind-generated waves with application to scatterometry. J. Geophys. Res. Ocean. 1987, 92, 4971-5029. [CrossRef]

108. Zavorotny, V.U.; Voronovich, A.G. Scattering of GPS signals from the ocean with wind remote sensing application. IEEE Trans. Geosci. Remote Sens. 2000, 38, 951-964. [CrossRef]

109. Rius, A.; Cardellach, E.; Martin-Neira, M. Altimetric Analysis of the Sea-Surface GPS-Reflected Signals. IEEE Trans. Geosci. Remote Sens. 2010, 48, 2119-2127. [CrossRef]

110. Staderini, E.M. UWB radars in medicine. IEEE Aerosp. Electron. Syst. Mag. 2002, 17, 13-18. [CrossRef]

111. Bilich. C.G. Bio-medical sensing using ultra wideband communications and radar technology: A feasibility study. IEEE Pervasive Health Conf. Workshops 2006, 29, 1-9.

112. Barrett, K.E.; Barman, S.M.; Boitano, S.; Brooks, H. Ganongs Review of Medical Physiology; McGraw-Hill Medical: New York, NY, USA, 2009; Volume 23, pp. 1-726.

113. Go, A.S.; Mozaffarian, D.; Roger, V.L.; Benjamin, E.J.; Berry, J.D.; Blaha, M.J.; Dai, S.; Ford, E.S.; Fox, C.S.; Franco, S.; et al. Executive summary: Heart disease and stroke statistics. Am. Heart Assoc. 2014, 129, 399-410.

114. Aladin, A.I.; Whelton, S.P.; Al-Mallah, M.H.; Blaha, M.J.; Keteyian, S.J.; Juraschek, S.P.; Rubin, J.; Brawner, C.A.; Michos, E.D. Relation of resting heart rate to risk for all-cause mortality by gender after considering exercise capacity (the Henry Ford exercise testing project). Am. J. Cardiol. 2014, 144, 701-706. [CrossRef]

115. Adib, F.; Mao, H.; Kabelac, Z.; Katabi, D.; Miller, R.C. Smart homes that monitor breathing and heart rate. In Proceedings of the 33rd Annual ACM Conference on Human Factors in Computing Systems, Seoul, Korea, 18 April 2015; Volume 18, pp. 837-846.

116. Patruno, J.; Fitrzyk, M.; Blasco, J.M.D. Monitoring and Detecting Archaeological Features with Multi-Frequency Polarimetric Analysis. Remote Sens. 2020, 12, 1. [CrossRef]

117. Banda, F.; Mariotti, M.A.; Tebaldin, S. Ground and Volume Decomposition as a Proxy for AGB from P-Band SAR Data. Remote Sens. 2020, 12, 240.

118. Geldsetzer, T.; Khurshid, S.K.; Warner, K.; Botelho, F.; Flett, D. Wind Speed Retrieval from Simulated radarSAT Constellation Mission Compact Polarimetry SAR Data for Marine Application. Remote Sens. 2019, 11, 1682. [CrossRef]

119. Carvalho, N.C.; Bins, L.S.; Anna, S.J. Analysis of Stochastic Distances and Wishart Mixture Models Applied on PolSAR Images. Remote Sens. 2019, 11, 2994. [CrossRef]

120. Yuzugullu, O.; Erten, E.; Hajnsek, I. Estimation of rice crop height from X-and C-band PolSAR by metamodel-based optimization. IEEE J. Sel. Top. Appl. Earth Obs. Remote Sens. 2017, 10, 194-204. [CrossRef]

121. Chiu, T.; Sarabandi, K. Electromagnetic scattering from short branching vegetation. IEEE Trans. Geosci. Remote Sens. 2000, 38, 911-925. [CrossRef]

122. Ferrazzoli, P.; Guerriero, L.; Solimini, D. Comparison between predicted performances of bistatic and monostatic radar in vegetation monitoring. In Proceedings of the Geoscience and Remote Sensing Symposium (IGARSS'94), Pasadena, CA, USA, 8-12 August 1994; Volume 3, pp. 1850-1852.

123. Bracaglia, M.; Ferrazzoli, P.; Guerriero, L. A fully polarimetric multiple scattering model for crops. Remote Sens. Environ. 1995, 54, 170-179. [CrossRef]

124. Brown, S.C.; Quegan, S.; Morrison, K.; Bennett, J.C.; Cookmartin, G. High-resolution measurements of scattering in wheat canopies-Implications for crop parameter retrieval. IEEE Trans. Geosci. Remote Sens. 2003, 41, 1602-1610. [CrossRef]

125. Onstott, R.G.; Moore, R.K.; Weeks, W.F. Surface-based scatterometer results of Arctic sea ice. IEEE Trans. Geosci. Electron. 1979, 17, 78-85. [CrossRef]

126. Wiesbeck, W. Radar of the future. In Proceedings of the IEEE European Radar Conference, Nuremberg, Germany, 9-11 October 2013; pp. 137-140. 
127. Mason, E.; Yonel, B.; Yazici, B. Deep learning for radar. In Proceedings of the 2017 IEEE Radar Conference (radarConf), Seattle, WA, USA, 8-12 May 2017; pp. 1703-1708.

128. Jokanovic, B.; Amin, M.; Ahmad, F. Radar fall motion detection using deep learning. In Proceedings of the 2016 IEEE Radar Conference (radarConf), Philadelphia, PA, USA, 2-6 May 2016; pp. 1-6.

129. Lameri, S.; Lombardi, F.; Bestagini, P.; Lualdi, M.; Tubaro, S. Landmine detection from GPR data using convolutional neural networks. In Proceedings of the 2017 25th European Signal Processing Conference (EUSIPCO), Kos, Greece, 28 August-2 September 2017; pp. 508-512.

130. Schwegmann, C.P.; Kleynhans, W.; Salmon, B.P.; Mdakane, L.W.; Meyer, R.G.V. Very deep learning for ship discrimination in Synthetic Aperture radar imagery. In Proceedings of the 2016 IEEE International Geoscience and Remote Sensing Symposium (IGARSS), Beijing, China, 10-15 July 2016; pp. 104-107.

131. Jackson, D.R.; Oliner, A.A. Leaky-Wave Antennas. In Modern Antenna Handbook Balanis; John Wiley Sons: New York, NY, USA, 2008.

132. Karmokar, D.K.; Guo, Y.J. Planar leaky-wave antennas for low-cost radar. In Proceedings of the 2017 IEEE-APS Topical Conference on Antennas and Propagation in Wireless Communications (APWC), Verona, WI, USA, 11-15 September 2017; pp. 112-115.

133. Roy, J.E. New results for the effective propagation constants of nonuniform plane waves at the planar interface of two lossy media. IEEE Trans. Antennas Propag. 2003, 51, 1206-1215. [CrossRef]

134. Baccarelli, P.; Frezza, F.; Simeoni, P.; Tedeschi, N. An Analytical Study of Electromagnetic Deep Penetration Conditions and Implications in Lossy Media through Inhomogeneous Waves. Materials 2018, 11, 1595. [CrossRef]

(C) 2020 by the authors. Licensee MDPI, Basel, Switzerland. This article is an open access article distributed under the terms and conditions of the Creative Commons Attribution (CC BY) license (http:/ / creativecommons.org/licenses/by/4.0/). 